\title{
Vicarious Calibration Data Screening Method Based on Variance of Surface Reflectance and Atmospheric Optical Depth Together with Cross Calibration
}

\author{
Kohei Arai 1 \\ 1 Graduate School of Science and Engineering \\ Saga University \\ Saga City, Japan
}

\begin{abstract}
Vicarious calibration data screening method based on the measured atmospheric optical depth and the variance of the measured surface reflectance at the test sites is proposed. Reliability of the various calibration data has to be improved. In order to improve the reliability of the vicarious calibration data, some screenings have to be made. Through experimental study, it is found that vicarious calibration data screening would be better to apply with the measured atmospheric optical depth and variance of the measured surface reflectance due to the facts that thick atmospheric optical depth means that the atmosphere contains serious pollution sometime and that large deviation of the surface reflectance from the average means that the solar irradiance has an influence due to cirrus type of clouds. As the results of the screening, the uncertainty of vicarious calibration data from the approximated radiometric calibration coefficient is remarkably improved. Also, it is found that cross calibration uncertainty is poorer than that of vicarious calibration.
\end{abstract}

Keywords-Vicarious calibration; Surface reflectance; Atmospheric Optical Depth; Sky-radiometer; Terra/ASTER; Satellite remote sensing

\section{INTRODUCTION}

Visible and Near Infrared mounted on earth observation satellites and the short-wavelength infrared radiation thermometer, Alternative calibration using measurement data on the ground and onboard calibration by the calibration mounting system is performed. For example, Marine Observation Satellite-1 [1], Landsat-7 Enhanced Thematic Mapper Plus [2], SeaWiFS [3], High Resolution Visible: HRV/SPOT-1 and 2 [4], Hyperion [5], POLDER [6], etc. by ASTER [7]. The calibration results have been reported. Further, report according to reciprocity with a uniform ground surface [8] over a wide area such as desert radiometer each other overlapping of the observation wavelength range have been made [9].

Vicarious calibration are conducted with consideration of the influence due to the atmosphere obviously [11]. Furthermore, the well-known cross calibration through comparisons among visible to near infrared radiometers onboard same or the different satellites is effective for calibration of the visible to near infrared radiometers in concern [12]. [13], [14]. To conduct the error analysis in the vicarious calibration of visible and near infrared radiometer,
Arai et al. made it clear dominant error factors of vicarious calibration accuracy [15]. According to it, most dominant error factors are the surface reflectance measurement followed by optical depth measurement that allows estimation of aerosol property. It is still difficult to estimate the aerosol characteristic and surface reflectance estimations. In order to estimate refractive index of aerosol particles, it is strongly suggested to use skyradiometer ${ }^{1}$ or aureole-meters [16], [17]. Since April 2003, Arai et al. have been doing the observation of aerosol by skyradiometer, POM-1 that is manufactured by PREDE Co. Ltd. [18]. The skyradiometer allows measurement of solar direct, diffuse and aureole that results in estimation of refractive index and size distribution of aerosol particles [19]. Nakajima proposes a method of estimating the volume particle size distribution and the complex refractive index [20]. Arai proposes a method for using the Simulated Annealing: SA as inverse problem-solving [21]. Furthermore, improved Modified Langley method as the calibration method of sky-radiometer and as the method for estimation of extraterrestrial solar irradiance as well as atmospheric optical depth is proposed by Arai. The method is for estimating the top of atmosphere radiance with consideration of not only down-welling but also up-welling $\mathrm{p}$ and s polarized irradiance and radiance [21].

Reliability of the vicarious calibration data has to be evaluated. Vicarious calibration data are used to be suffered from atmospheric conditions, existing cirrus clouds, smoke from wild fire that happens nearby test sites, enthused gasses from automobiles that situated nearby the test sites, and so on. These are invisible mostly. Therefore, vicarious calibration data are suffered from these influences even if we conducted field campaigns with great care about these. It is possible to find such these influences through careful screening test with the measured data of surface reflectance and optical depth. The method proposed here is to make a screening the vicarious calibration data suffered from the influences for improvement uncertainty of the vicarious calibration data.

In the next section, the method and procedure of the proposed screening method is described followed by experimental data and estimated results. Then conclusion is described with some discussions.

\footnotetext{
${ }^{1}$ http://skyrad.sci.u-toyama.ac.jp/
} 


\section{PROPOSED METHOD}

\section{A. Vicarious Calibration Method}

Flowchart of the reflectance based vicarious calibration method is shown in Figure 1. At the test site (relatively high surface reflectance of homogeneous area of desert which is situated at comparatively high elevation (thin atmosphere) is desired, field campaign is used to be conducted. At the field campaign, atmospheric optical depth, surface reflectance, column ozone, column water vapor is measured. From the measured atmospheric optical depth, size distribution can be estimated using Angstrome exponent together with extraterrestrial solar irradiance through Langley plot. Total atmospheric optical depth can be divided into Rayleigh scattering component due to atmospheric continuant, and Mie scattering component due to aerosol particles in the scattering components. On the other hand, absorption components due to water vapor, ozone and aerosols are also estimated. Rayleigh scattering component can be estimated with air-temperature and atmospheric pressure on the ground. Absorption due to ozone can be estimated with the absorption coefficient of ozone and the measured column ozone in unit of Dobson Unit. In the visible to near infrared wavelength region, major contribution is from atmospheric continuant $\left(\mathrm{O}_{2}, \mathrm{~N}_{2}\right)$, water vapor, ozone, and aerosols. Therefore, these contributions in the forms of scattering and absorption have to be taken into account. Through radiative transfer equation solving process (mostly MODTRAN code is used to use) with the estimated influencing aforementioned parameters, Top of the Atmosphere: TOA radiance (at sensor radiance) can be estimated. Then the estimated TOA radiance is compared with satellite sensor data (Digital Number; $\mathrm{DN}$ is converted to radiance). Thus gain can be calibrated. This gain degradation is called as Radiometric Calibration Coefficient: RCC. It is referred to Vicarious Calibration Coefficient: RCCvic. On the other hands, most of visible to near infrared radiometer onboard satellites has own onboard calibration system. It provides Onboard Calibration Coefficient (OBC).

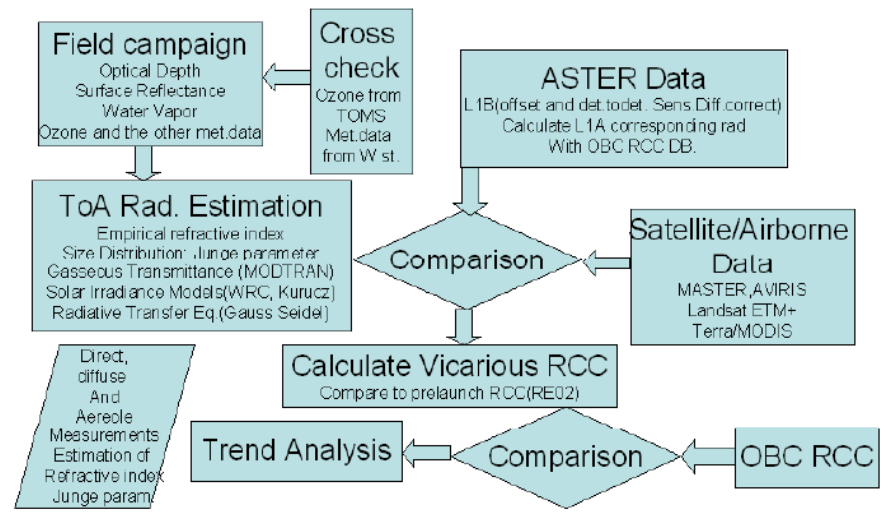

Fig. 1. Flowchart of reflectance based vicarious calibration method

Then it is possible to compare both coefficients.

\section{B. Error Budget Analysis}

There are 8 error sources for the vicarious calibration. The result from error budget analysis of the vicarious calibration method is shown in Table 1.
TABLE I. ERROR BUDGET FOR REFLECTANCE BASED VICARIOUS CALIBRATION METHOD

\begin{tabular}{|l|l|l|}
\hline Error sources & Error Type & Error (\%) \\
\hline Optical depth & Random & 1.5 \\
\hline Surface reflectance measurement instrument & Random & 2 \\
\hline Standard plaque & Systematic & 1 \\
\hline Averaging & Random & 0 \\
\hline Refractive index & Random & 1.8 \\
\hline Size distribution & Random & 2 \\
\hline Radiative transfer code & Systematic & 1 \\
\hline Registration & Random & 1 \\
\hline RSS & & 4.06 \\
\hline
\end{tabular}

Optical depth measurement has error of $1.5 \%$ while surface reflectance measurement instrument has $2 \%$ of error which includes Bi-Directional Reflectance Distribution Function: BRDF effect. Standard plaque is used as reference of reflectance and has $1 \%$ of error. Estimation accuracy of refractive index and size distribution is not high enough. 1.8 and $2 \%$ of errors are suspected for each. Radiative transfer code has $1 \%$ of error while $1 \%$ of error is suspected due to registration of test site (location identification) in the satellite sensor image. Thus $4.06 \%$ error is suspected for vicarious calibration.

\section{Vicarious Calibration Data Screening Method}

Reliability of the vicarious calibration data has to be evaluated. Vicarious calibration data are used to be suffered from atmospheric conditions, existing cirrus clouds, smoke from wild fire which happens nearby test sites, enthused gasses from automobiles which situated nearby the test sites, and so on. These are invisible mostly. Therefore, vicarious calibration data are suffered from these influences even if we conduct field campaigns with great care about these. It is possible to find such these influences through careful screening test with the measured data of surface reflectance and optical depth. The method proposed here is to make a screening the vicarious calibration data suffered from the influences for improvement uncertainty of the vicarious calibration data. There are two major factors, optical depth and standard deviation of the measured surface reflectance. By using threshold, vicarious calibration data can be screened.

\section{Uncertainty of Vicarious Calibration}

Time series of RCCvic data can be approximated with appropriate function (Usually single exponential function of "a $\operatorname{EXP}(-b$ d $)+c$ ") in the sense of trend analysis. Let be RCCvic' denotes the approximated RCCvic. Then uncertainty of vicarious calibration can be expressed in equation (1).

$\mathrm{U}=\operatorname{SQRT}\left(\Sigma(\text { RCCvic-RCCvic' })^{2} / \mathrm{n}_{\mathrm{i}}\left(\mathrm{n}_{\mathrm{i}}-\mathrm{p}_{\mathrm{i}}\right)\right)$

where $\mathrm{n}$ and $\mathrm{p}$ denotes the number of vicarious calibration data and the condition number, respectively. Thus uncertainty of the vicarious calibration can be calculated. 


\section{EXPERIMENT}

\section{A. Trend of the Vicarious Calibration Data}

One of examples of vicarious calibration data of ASTER/VNIR onboard Terra satellite is shown in Figure 2

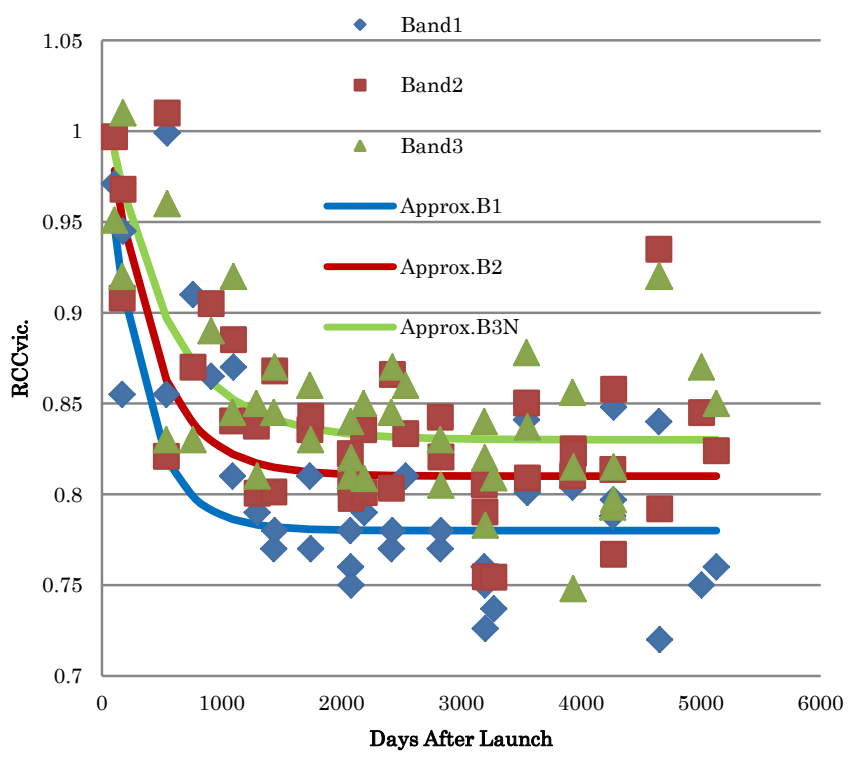

Fig. 2. Vicarious calibration data of ASTER/VNIR onboard Terra satellite

ASTER/VNIR onboard Terra satellite was launched in December 1999. This is approximately 15 years data. Solid lines are approximated function with the single exponential function. It is clear that vicarious calibration data are scattered because there are many data which are influenced by the smoke due to wild fire, exhausted gasses from automobile, cirrus, etc. VNIR has three spectral bands, 1 to 3 which are corresponding to green, red and near infrared bands.

Table 2 shows the coefficients of the approximation function of vicarious calibration data as a function of days after launch, $\mathrm{x}$.

TABLE II. COEFFICIENTS OF THE APPROXIMATION FUNCTION OF VICARIOUS CALIBRATION DATA AS A FUNCTION OF DAYS AFTER LAUNCH, X

\begin{tabular}{|l|l|l|l|}
\hline $\mathrm{y}=\mathrm{b} 0 * \exp (-\mathrm{b} 1 * \mathrm{x})+\mathrm{b} 2$ & Band1 & \multicolumn{1}{l|}{ Band2 } & \multicolumn{1}{l|}{ Band3 } \\
\hline $\mathrm{b} 0$ & 0.2374657 & 0.2227815 & 0.194918 \\
\hline $\mathrm{b} 1$ & 0.0033325 & 0.0026667 & 0.0019807 \\
\hline $\mathrm{b} 2$ & 0.7551861 & 0.83 & 0.8468567 \\
\hline
\end{tabular}

The difference between vicarious calibration data and the approximated vicarious calibration data is shown in Table 3 while uncertainty of vicarious calibration data defined in equation (1) is shown in Table 4, respectively.

TABLE III. DIFFERENCE BETWEEN VICARIOUS CALIBRATION DATA AND THE APPROXIMATED VICARIOUS CALIBRATION DATA

\begin{tabular}{|c|c|c|}
\hline Band1 & Band2 & Band3 \\
\hline 0.161 & 0.071 & 0.071 \\
\hline
\end{tabular}

TABLE IV. UNCERTAINTY OF VICARIOUS CALIBRATION DATA DEFINED IN EQUATION (1)

\begin{tabular}{|c|r|r|}
\hline Band1 & \multicolumn{1}{|l|}{ Band2 } & \multicolumn{1}{l|}{ Band3 } \\
\hline 0.0101579 & 0.0067297 & 0.0067447 \\
\hline
\end{tabular}

\section{B. Vicarious Calibration Data After the Screening}

Figure 3 shows the vicarious calibration data trend after the screening.

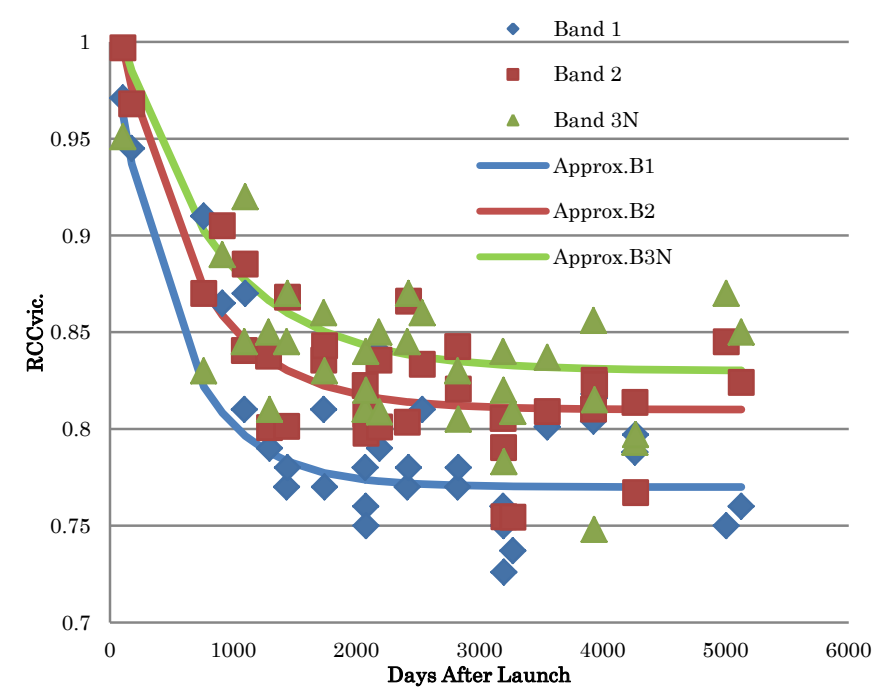

Fig. 3. Vicarious calibration data trend after the screening

One of the examples of the measured surface reflectance for test site of Railroad Valley Playa in Nevada, USA which is acquired on 25 September 2015 is shown in Figure 4 while one if examples of the measured surface reflectance without screening of the test site Ivanpah Playa in California, USA which is acquired on 18 September 2015 is shown in Figure 4 (b), respectively.

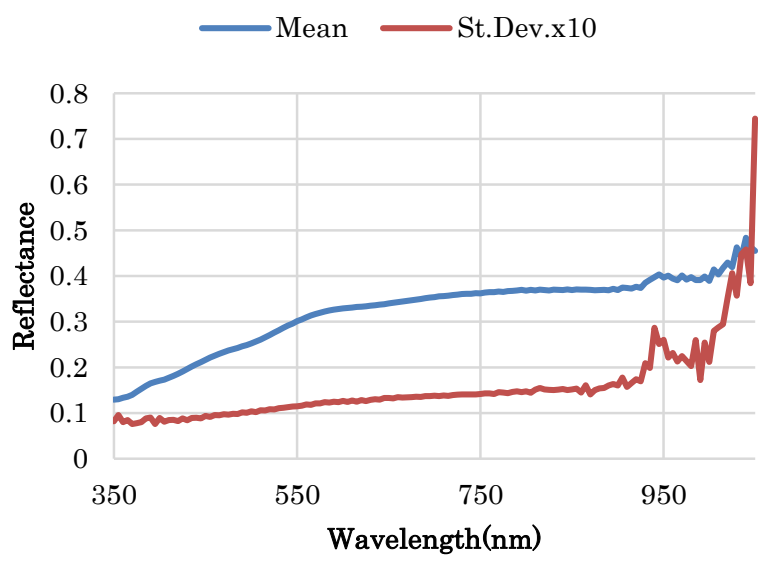

(a)Railroad Valley Playa 


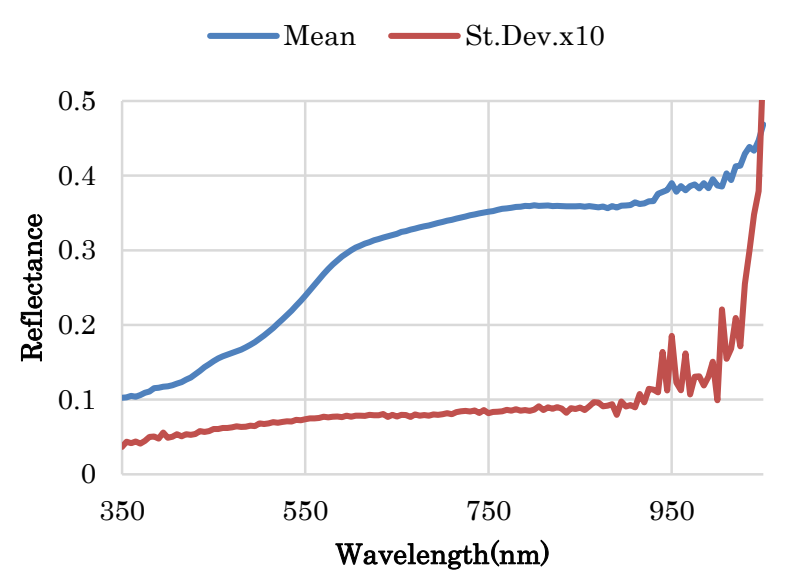

(b)Ivanpah Playa

Fig. 4. Measured surface reflectance at the test sites

As shown in Figure 4, the measured surface reflectance between Ivanpah and Railroad Valley Playas are almost same while standard deviation of surface reflectance is quite different (standard deviation of Ivanpah playa is approximately $50 \%$ greater than that of Railroad Valley playa). Figure 5 (a) shows ASTER/VNIR image of Ivanpah playa while Figure 5 (b) shows that of Railroad Valley playa. Meanwhile, Figure 5 (c) shows ASTER/TIR image of Railroad Valley playa which shows the suspected existing cirrus. Although cirrus clouds cannot be seen in the ASTER/VNIR image of Railroad Valley playa, ASTER/TIR image shows existing of cirrus clouds almost all over the test site area. During the surface reflectance measurement, solar irradiance is changed a lot due to the existing cirrus. Therefore, the standard deviation of the measured surface reflectance is $50 \%$ much greater than that of Ivanpah playa. We would better to omit such unreliable vicarious calibration data.

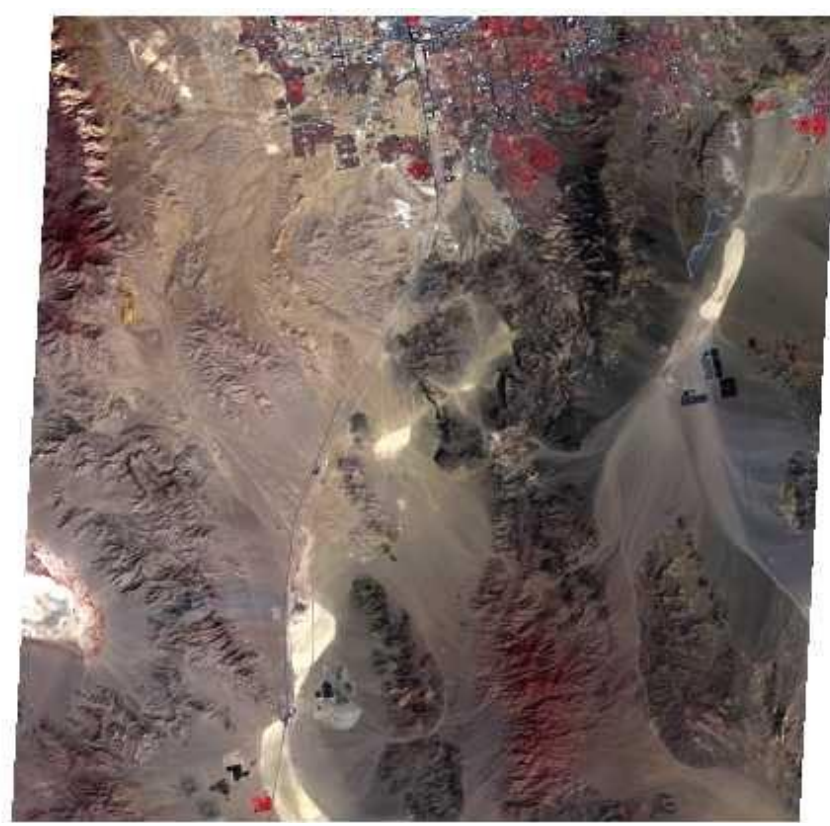

(a)VNIR image of Ivanpah

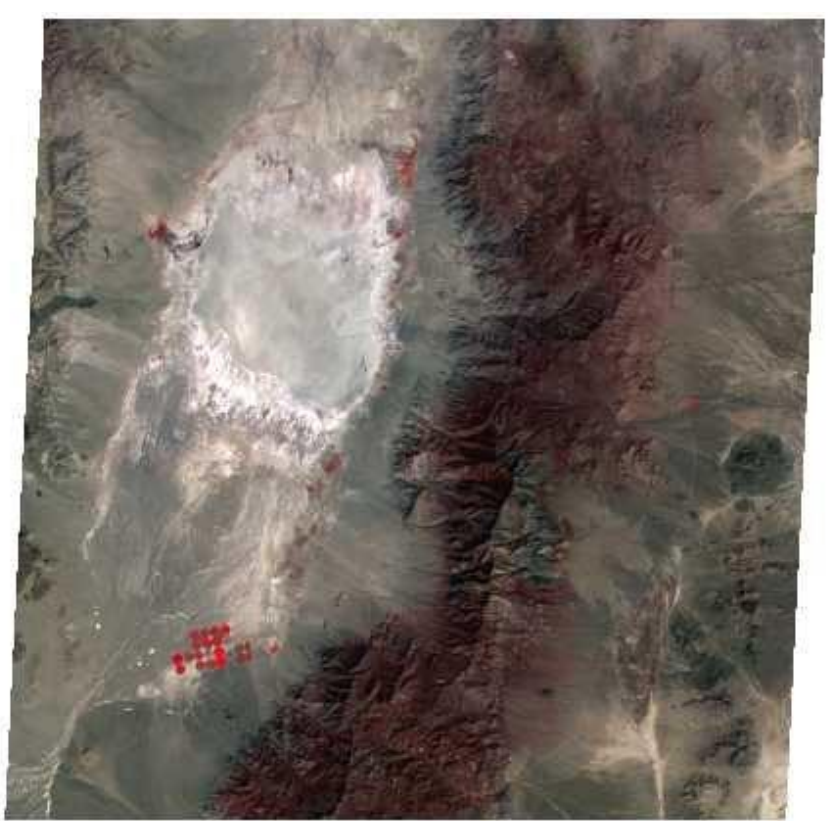

(b)VNIR image of Railroad Valley

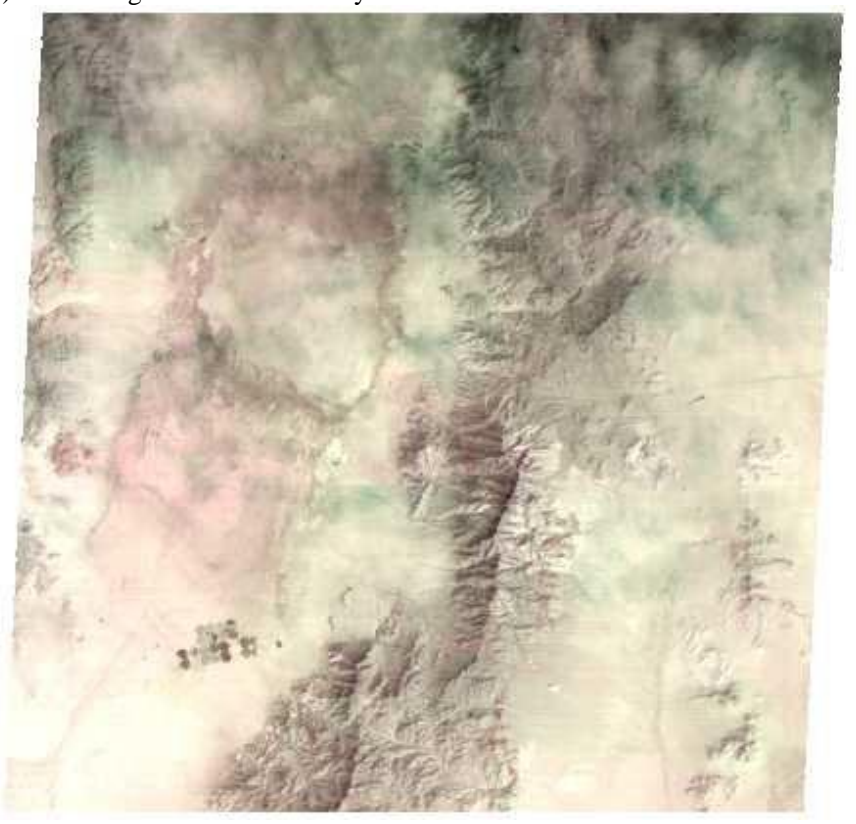

(c)TIR image of Railroad Valley

Fig. 5. ASTER/VNIR and TIR images of Ivanpah and Railroad Valley playas

Table 5 shows the coefficients of the approximation function of vicarious calibration data after the screening as a function of days after launch, $x$.

TABLE V. COEFFICIENTS OF THE APPROXIMATION FUNCTION OF VICARIOUS CALIBRATION DATA AFTER THE SCREENING AS A FUNCTION OF DAYS AFTER LAUNCH, $X$

\begin{tabular}{|l|l|l|r|}
\hline $\mathrm{y}=\mathrm{b} 0 * \exp (-\mathrm{b} 1 * \mathrm{x})+\mathrm{b} 2$ & \multicolumn{1}{l|}{ Band1 } & \multicolumn{1}{l|}{ Band2 } & \multicolumn{1}{l|}{ Band3 } \\
\hline $\mathrm{b} 0$ & 0.2374657 & 0.2227815 & 0.194918 \\
\hline $\mathrm{b} 1$ & 0.002 & 0.0016667 & 0.0013 \\
\hline $\mathrm{b} 2$ & 0.77 & 0.81 & 0.83 \\
\hline
\end{tabular}


The difference between vicarious calibration data and the approximated vicarious calibration data is shown in Table 6 while uncertainty of vicarious calibration data defined in equation (1) is shown in Table 7, respectively.

TABLE VI. DIFFERENCE BETWEEN VICARIOUS CALIBRATION DATA AND THE APPROXIMATED VICARIOUS CALIBRATION DATA

\begin{tabular}{|c|c|c|}
\hline Band1 & Band2 & Band3 \\
\hline 0.040 & 0.024 & 0.036 \\
\hline
\end{tabular}

TABLE VII. UNCERTAINTY OF VICARIOUS CALIBRATION DATA DEFINED IN EQUATION (1)

\begin{tabular}{|c|r|r|}
\hline Band1 & \multicolumn{1}{|l|}{ Band2 } & \multicolumn{1}{l|}{ Band3 } \\
\hline 0.0061288 & 0.0047501 & 0.0058725 \\
\hline
\end{tabular}

It is found that uncertainty of vicarious calibration can be improved remarkably in particular for Band 1.

\section{Error Budget Analysis of Cross Calibration}

MISR and MODIS sensors are onboard Terra satellite as well. The spectral coverage of MISR and MODIS are overlapped with ASTER/VNIR. Therefore, cross calibration can be done for VNIR and MISR (VNIR Band 1, 2,3) and VNIR and MODIS (VNIR Band 2 and 3). Due to the fact that MODIS does not have the corresponding band for VNIR Band 1 , cross calibration cannot be done. The results from error budget analysis are shown in Table 8. In the proposed cross calibration, it is conducted at the same dates for field campaigns because the vicarious calibration data can be used for cross calibration.

TABLE VIII. ERROR BUDGET FOR CROSS CALIBRATION

\begin{tabular}{|l|l|l|}
\hline Error items & Error sources & $\begin{array}{l}\text { Error } \\
(\%)\end{array}$ \\
\hline $\begin{array}{l}\text { Uncertainty of the instruments for } \\
\text { comparison }\end{array}$ & MISR,MODIS & 4.06 \\
\hline Registration & $\begin{array}{l}\text { Uniformity of the surface } \\
\text { reflectance }\end{array}$ & 2 \\
\hline Spectral response & Surface reflectance & 1.5 \\
\cline { 2 - 3 } & Atmospheric effect & 1 \\
\hline RSS & & 4.87 \\
\hline
\end{tabular}

\section{Cross Calibration Results with MISR}

Figure 6 shows the cross calibration data trend derived RCC (RCCcross) with MISR. It is possible to approximate with the same function of the single exponential function as a function of days after launch, x. The coefficients of the approximation function are shown in Table 9 while the difference between cross calibration data and the approximated data are shown in Table 10. Uncertainty defined as equation (1) for cross calibration with MISR is shown in Table 11. In comparison to the uncertainty of the vicarious calibration, cross calibration accuracy is not better than vicarious calibration obviously. It, however, is useful to find the biases between ASTER/VNIR and MISR.

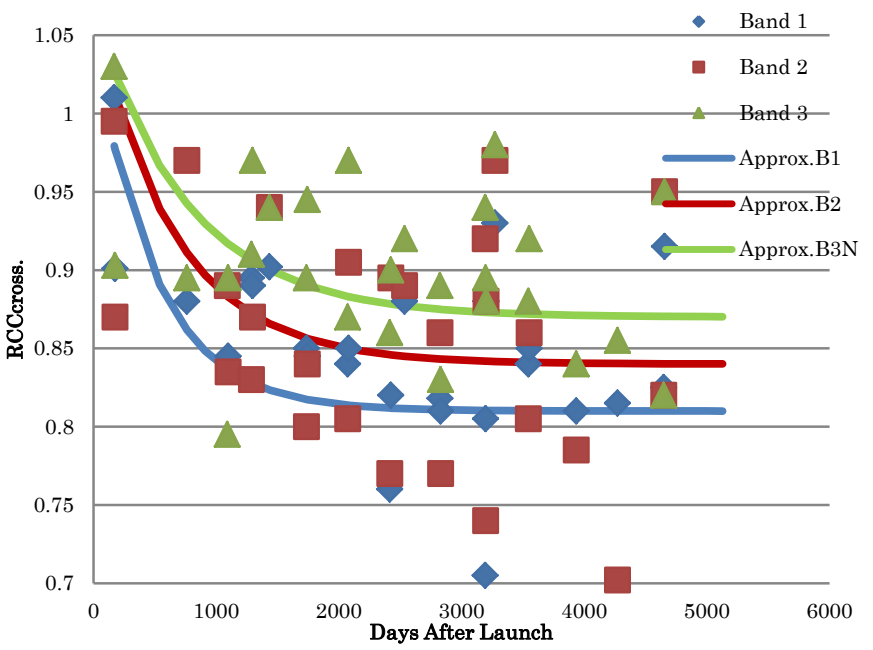

Fig. 6. Cross calibration data of ASTER/VNIR with MISR onboard Terra satellite

TABLE IX. COEFICIENTS OF THE APPROXIMATION FunCTION OF CROSS CALIBRATION DATA AFTER THE SCREENING AS A FUNCTION OF DAYS AFTER LAUNCH, $\mathrm{X}$

\begin{tabular}{|l|l|l|r|}
\hline $\mathrm{y}=\mathrm{b} 0 * \exp (-\mathrm{b} 1 * \mathrm{x})+\mathrm{b} 2$ & \multicolumn{1}{l|}{ Band1 } & \multicolumn{1}{l|}{ Band2 } & \multicolumn{1}{l|}{ Band3 } \\
\hline $\mathrm{b} 0$ & 0.2374657 & 0.2227815 & 0.194918 \\
\hline $\mathrm{b} 1$ & 0.002 & 0.0015 & 0.0013 \\
\hline $\mathrm{b} 2$ & 0.81 & 0.84 & 0.87 \\
\hline
\end{tabular}

TABLE X. DiFFERENCE BETWEEN CROSS CALIBRATION DATA AND THE APPROXIMATED VICARIOUS CALIBRATION DATA

\begin{tabular}{|r|r|r|}
\hline Band1 & Band2 & Band3 \\
\hline 8.985 & 9.844 & 10.508 \\
\hline
\end{tabular}

TABLE XI. UNCERTAINTY OF CROSS CALIBRATION DATA DEFINED IN EQUATION (1)

\begin{tabular}{|l|l|l|}
\hline Band1 & Band2 & Band3 \\
\hline 0.0759393 & 0.0794899 & 0.0821237 \\
\hline
\end{tabular}

\section{E. Cross Calibration Results with MODIS}

Figure 7 shows the cross calibration data trend derived RCC (RCCcross) with MODIS. It is possible to approximate with the same function of the single exponential function as a function of days after launch, x. The coefficients of the approximation function are shown in Table 12 while the difference between cross calibration data and the approximated data are shown in Table 13. Uncertainty defined as equation (1) for cross calibration with MODIS is shown in Table 14. In comparison to the uncertainty of the vicarious calibration, cross calibration accuracy is not better than vicarious calibration obviously. It, however, is useful to find the biases between ASTER/VNIR and MODIS. 


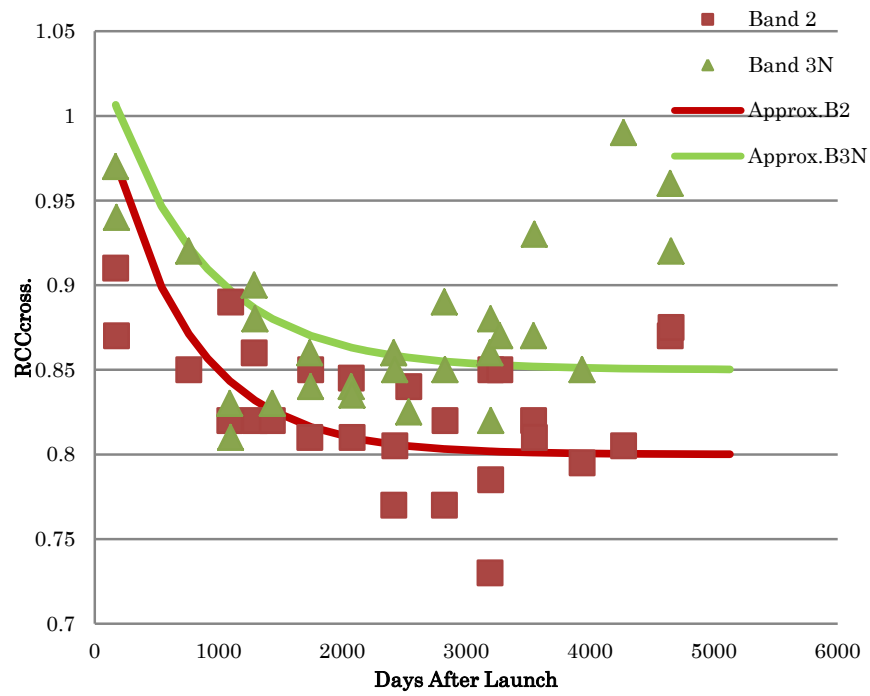

Fig. 7. Cross calibration data of ASTER/VNIR with MODIS onboard Terra satellite

TABLE XII. COEFFICIENTS OF THE APPROXIMATION FUNCTION OF CROSS CALIBRATION DATA AFTER THE SCREENING AS A FUNCTION OF DAYS AFTER LAUNCH, X

\begin{tabular}{|l|l|l|r|}
\hline $\mathrm{y}=\mathrm{b} 0 * \exp (-\mathrm{b} 1 * \mathrm{x})+\mathrm{b} 2$ & Band1 & \multicolumn{1}{l|}{ Band2 } & \multicolumn{1}{l|}{ Band3 } \\
\hline $\mathrm{b} 0$ & - & 0.222781456 & 0.194918032 \\
\hline $\mathrm{b} 1$ & - & 0.0015 & 0.0013 \\
\hline $\mathrm{b} 2$ & - & 0.8 & 0.85 \\
\hline
\end{tabular}

TABLE XIII. Difference Between Cross Calibration Data AND the APPROXIMATED VICARIOUS CALIBRATION DATA

\begin{tabular}{|r|r|r|}
\hline Band1 & Band2 & Band3 \\
\hline- & 8.884 & 10.035 \\
\hline
\end{tabular}

TABLE XIV. UNCERTAINTY OF CROSS CALIBRATION DATA DEFINED IN EQUATION (1)

\begin{tabular}{|r|l|l|}
\hline Band1 & Band2 & Band3 \\
\hline 0 & 0.075513481 & 0.080253544 \\
\hline
\end{tabular}

As the results from the uncertainty evaluations of the cross calibration between ASTER/VNIR and MISR as well as MODIS, it is almost same between cross calibrations of ASTER/VNIR and MISR as well as MODIS. It is also found that the uncertainty of cross calibration is poorer than that of vicarious calibration.

\section{CONClusion}

Vicarious calibration data screening method based on the measured atmospheric optical depth and the variance of the measured surface reflectance at the test sites is proposed. Reliability of the various calibration data has to be improved. In order to improve the reliability of the vicarious calibration data, screening has to be made. Through experimental study, it is found that vicarious calibration data screening would be better to apply with the measured atmospheric optical depth and variance of the measured surface reflectance due to the facts that thick atmospheric optical depth means that the atmosphere contains serious pollution sometime and that large deviation of surface reflectance from the average means that the solar irradiance has influence due to cirrus type of clouds. As the results of the screening, the uncertainty of vicarious calibration data from the approximated radiometric calibration coefficient is remarkably improved. Also, it is found that cross calibration uncertainty is poorer than that of vicarious calibration.

\section{ACKNOWLEDGEMENTS}

Author would like to thank Dr. Akira Ono of National Institute of Advanced Industrial Science and Technology: AIST for his initiating of this research works. Also, author would like to thank Dr. Satoshi Tsuchida and his research staff, Japanese Space Systems: JSS members together with Dr. Kurtis Thome of NASA/GSFC as well as Prof. Dr. Stuart Biggar and his research staff for their contributions of the field experiments and valuable discussions.

\section{REFERENCES}

[1] Arai K., Preliminary assessment of radiometric accuracy for MOS-1 sensors, International Journal of Remote Sensing, 9, 1, 5-12, 1988.

[2] Barker, JL, SK Dolan, et al., Landsat-7 mission and early results, SPIE, 3870, 299-311, 1999.

[3] Barnes, RA, EEEplee, et al., Changes in the radiometric sensitivity of SeaWiFS determined from lunar and solar based measurements, Applied Optics, 38, 4649-4664, 1999.

[4] Gellman, DI, SF Biggar, et al., Review of SPOT-1 and 2 calibrations at White Sands from launch to the present, Proc. SPIE, Conf.No.1938, 118-125, 1993.

[5] Folkman, MA, S.Sandor, et al., Updated results from performance characterization and calibration of the TRWIS III Hyperspectral Imager, Proc. SPIE, 3118-17, 142, 1997.

[6] Hagolle, O., P.Galoub, et al., Results of POLDER in-flight calibration, IEEE Trans. On Geoscience and Remote Sensing, 37, 1550-1566, 1999.

[7] Thome, K., K. Arai, S. Tsuchida and S. Biggar, Vicarious calibration of ASTER via the reflectance based approach, IEEE transaction of GeoScience and Remote Sensing, 46, 10, 3285-3295, 2008.

[8] Cosnefroy, H., M.Leroy and X.Briottet, Selection and characterization of Saharan and Arabian Desert sites for the calibration of optical satellite sensors, Remote Sensing of Environment, 58, 110-114, 1996.

[9] Arai, K., In-flight test site cross calibration between mission instruments onboard same platform, Advances in Space Research, 19, 9, 1317-1328, 1997.

[10] Nicodemus, FE, "Directional Reflectance and Emissivity of an Opaque Surface", Applied Optic (1965), or FE Nicodemus, JC Richmond, JJ Hsia, IW Ginsber, and T. Limperis, "Geometrical Considerations and Nomenclature for Reflectance, ", NBS Monograph 160, US Dept. of Commerce (1977).

[11] Slater, PN, SFBiggar, RGHolm, RDJackson, Y.Mao, MSMoran, JMPalmer and B.Yuan, Reflectance-and radiance-based methods for the in-flight absolute calibration of multispectral sensors, Remote Sensing of Environment, 22, 11-37, 1987.

[12] Kieffer, HH and RL Wildey, Establishing the moon as a spectral radiance standard, J., Atmosphere and Oceanic Technologies, 13, 360375, 1996.

[13] Arai, K., Atmospheric Correction and Residual Errors in Vicarious Cross-Calibration of AVNIR and OCTS Both Onboard ADEOS, Advances in Space Research, 25, 5, 1055-1058, 1999.

[14] Liu;. JI, Z. Li, YL Qiao, Y.-J. Liu, and Y.-X. Zhang, A new method for cross-calibration of two satellite sensors, Int J. of Remote Sensing, 25 , $235267-5281,2004$. 
[15] Kohei Arai, error analysis of vicarious calibration of satellite visible and near infrared radiometer based KJThome, reflectance, Japan Photogrammetry Journal, Vol.39, No.2, pp.99-105, (2000 ) .

[16] Arai, K., Vicarious calibration for solar reflection channels of radiometers onboard satellites with deserted area of data, Advances in Space Research, 39, 1, 13-19, 2006.

[17] Arai, K. and X.Liang, Characterization of aerosols in Saga city areas, Japan withy direct and diffuse solar irradiance and aureole observations, Advances in Space Research, 39, 1, 23-27, 2006.

[18] Kohei Arai , vicarious calibration of ASTER / VNIR based on long-term observations of the optical properties of aerosols in Saga, Journal of the Remote Sensing Society of Japan , 28,3,246 over 255,2008

[19] Kohei Arai , applied linear algebra, modern science , Inc. , 2006

[20] Nakajima, T., M.Tanaka and T. Yamauchi, Retrieval of the optical properties of aerosols from aureole and extinction data, Applied Optics, 22, 19, 2951-2959, 1983.

[21] Kohei Arai , Xing Ming Liang, Estimation of complex refractive index of aerosol using direct solar direct, diffuse and aureole by simulated annealing, and polarized radiance -simultaneous estimation of particle size distribution and refractive index, Journal of the Remote Sensing Society of Japan, Vol.23, No.1, pp .11-20,2003 .

\section{AUTHORS PROFILE}

Kohei Arai, He received BS, MS and PhD degrees in 1972, 1974 and 1982, respectively. He was with The Institute for Industrial Science and Technology of the University of Tokyo from April 1974 to December 1978 also was with National Space Development Agency of Japan from January, 1979 to March, 1990. During from 1985 to 1987, he was with Canada Centre for Remote Sensing as a Post Doctoral Fellow of National Science and Engineering Research Council of Canada. He moved to Saga University as a Professor in Department of Information Science on April 1990. He was a councilor for the Aeronautics and Space related to the Technology Committee of the Ministry of Science and Technology during from 1998 to 2000. He was a councilor of Saga University for 2002 and 2003. He also was an executive councilor for the Remote Sensing Society of Japan for 2003 to 2005 . He is an Adjunct Professor of University of Arizona, USA since 1998. He also is Vice Chairman of the Commission "A" of ICSU/COSPAR since 2008. He wrote 33 books and published 500 journal papers. He is now Editor-in-Chief of IJACSA and IJISA. 